\title{
Study on footstep power generation using piezoelectric tile
}

\author{
Anis Maisarah Mohd Asry, Farahiyah Mustafa, Sy Yi Sim, Maizul Ishak, Aznizam Mohamad \\ Faculty of Engineering Technology, Universiti Tun Hussein Onn Malaysia, Malaysia
}

\begin{tabular}{l}
\hline Article Info \\
\hline Article history: \\
Received Oct 14, 2018 \\
Revised Feb 15, 2019 \\
Accepted Mar 29, 2019 \\
\hline
\end{tabular}

\section{Keywords:}

Footstep power generation Full-wave bridge rectifier Piezoelectric transducer Power generation Vibration energy

\begin{abstract}
Electrical energy is important and had been demand increasingly. A lot of energy resources have been wasted and exhausted. An alternative way to generate electricity by using a population of human had been discovered When walking, the vibration that generates between the surface and the footstep is wasted. By utilizing this wasted energy, the electrical energy can be generated and fulfill the demand. The transducer that use to detect the vibration is a piezoelectric transducer. This transducer converts the mechanical energy into electrical energy. When the pressure from the footstep is applied to the piezoelectric transducer, it will convert the pressure or the force into the electrical energy. The piezoelectric transducer is connected in series-parallel coonection. Then, it is placed on the tile that been made from wood as a model for footstep tile to give pressure to the piezoelectric transducers. This tile can be placed in the crowded area, walking pavement or exercise instruments. The electric energy that generates from this piezoelectric tile can be power up low power appliances.
\end{abstract}

Copyright $@ 2019$ Institute of Advanced Engineering and Science. All rights reserved.

\section{Corresponding Author:}

Farahiyah Mustafa,

Faculty of Engineering Technology,

Universiti Tun Hussein Onn Malaysia,

Hub Pendidikan Tinggi Pagoh, 86400 Pancur, Johor, Malaysia.

Email: farahiyah@uthm.edu.my

\section{INTRODUCTION}

Increasing in depletion of fossil fuel and non-renewable energy has been demanded a critical needed for another alternative source of energy to replace the depletion and continuously supply the increasing of energy request. Energy is the ability to do work [1]. Electricity is one of the commonly used energy and it is increasing in line with people. The objective in this invention is to use the increasing of human population and give high impact in increasing the energy while reducing the negative effect on the environment. This utilizes power also do not depend or rely on the climate condition [2].

In order to generate the electricity needed, the wasted energy needs to be utilized. The energy is wasted from walking activities done by a human can be used to generate electricity. The walking energy is wasted in the form of the vibration to the surface [3,4]. The average human footstep can take about 3000 -5000 steps a day [5-6]. This footstep can generate more electricity to achieve the demand needed. The energy from footstep can be extracted by vibration and electromagnatic, electrostatic and piezoelectric are the three types of vibration to electrical energy conversion [7].

Generally, there are different techniques in generating electrical energy that are received from the people movement or vechicles movement on roads. An unfamiliar method is used for the fluctuation of pressure in the ground that is formed by crossing of people or vechicles that are exposed and resulting a fixed pressure amplitude [8]. For an example, in the Netherland, the electromagnetic generator is apply on the dance floor to generate electricity. However, a relatively larger deflection of floor up to $10 \mathrm{~mm}$ is needed to generate noticeable electric energy. Additionally, its have a complex structure and demand in high assembling cost [9]. In Japan, the piezoelectric transducer had been installed in the floor of the subway ticket machine to generate electricity and only need piezoceramic without any complex mechanical structure [8-9]. 
In this method, the energy conversion is based on piezoelectric effect. There are two categories of piezoelectric effect which are direct piezoelectric effect and converse piezoelectric effect $[10,11]$

The direct piezoelectric effect is the ability of the piezoelectric transducer to convert the mechanical energy to electrical energy [12-14]. When vibration or mechanical stress are applied on the piezoelectric transducer, it will deformed and produced electric charge. It is also known as generator or transducer effect [15]. The ability of the piezoelectric transducer to convert the electrical energy into the mechanical energy is known as converse piezoelectric effect $[14,15]$ The piezoelectric transducer will deformed when the piezoelectric transducer is subjected to the electric field or the electric field is applied to the electric field. This also known as actuator or motor effect $[13,14,16]$

The vibration energy harvesting operation starts with extracting mechanical vibration energy from the environment and rectifying the alternating current (AC) voltage produced and converting it into a direct current (DC) voltage. By using the piezoelectric effect, the wasted energy can be used to generate the electricity. When pressure and strain are applied to the piezoelectric material, it will generate electrical energy by converting the mechanical energy from the footstep [17-19]. Piezoelectric materials can be used as mechanisms to transfer mechanical energy, usually ambient vibration, into electrical energy that can be stored and used to power other devices [20]. The electrical energy from a piezoelectric transducer coupled to a vibration system is usually very low, depending on load and generated AC source. Therefore, it is necessary to develop an interface circuit that makes the conversion to DC. The full-wave bridge rectifier is used in order to convert the AC into DC, then filter the waveform and stored it into the capacitor that acts as a storage. This piezoelectric transducer is connected to each other and placed it on footpaths, stairs, platforms or in populated areas. The voltage that generated from this piezoelectric transducer can be used to power up the low power appliances such as road light, street light and sigh boards of streets [2]. The voltage can be stored in the battery and also in the capacitor before being used as the voltage generated from the piezoelectric is low.

Research has been done in generating the power energy by using piezoelectric transducer. Arvind et.al proposed a power generation through human locomotion [21]. It generate the electricity by placing the circular piezoelectric transducer in the pedestrians and used it to light the street lights. Another research was done by Ghosh et al., and they proposed electrical power generation using footstep for urban area energy application [22]. In this research, they are using sources from human motion to press the gear and the shaft to create electrical energy by rotational motion and using the faraday law concept [22]. Besides that piezoelectric transducer also can be used in medical purpose. For this study, Meirer et al., proposed a piezoelectric energy harvesting shoe system for podiatric sensing [23]. This study is implement the circular piezoelectric transducer in the heels of the shoes and it targeted to the athletes, physical therapy patients, amputees, and those with muscular or nervous system disorders [23]. Another research had been done by Akshat Kamboj et.al, design of footstep power generator using piezoelectric sensors [24]. This study also used circular piezoelectric transducer to generate power by using footstep. The power generate is stored in two batteries which is 6 volt for each batteries before using to running the load such as light [24].

In Bangladesh, by using its population density, the electrical energy can be generate by using the piezoelectric material that had been study by Nayan HR. In this study, 12 piezoelectric sensor is used in 1 square $\mathrm{ft}$ and by using $50 \mathrm{~kg}$ weight pressure from single person, the minimum voltage per step is $1 \mathrm{~V} \mathrm{[25].}$ It takes 800 steps to increase $1 \mathrm{~V}$ charge in battery, so to increase $12 \mathrm{~V}$ in battery it needs 9600 steps. If in 1 seconds the average of footstep is 2 step, then it take 80 minutes to achive 9600 steps [25].

In this study, the development of power generation by using piezoelectric tile has been studied. The piezoelectric transducer generate electrical energy by converting the pressure applied on it. The sources of pressure is from the weight of the people walking over it. The 6 cell of piezoelectric transducers is attach together in series-parallel connection. The output of this piezoelectric transducer is in AC voltage and not a steady output. So a full wave bridge rectifier is used to convert the AC voltage into DC voltage, then the voltage is filtered by the smoothing capacitor to filter out any fluctuations in the output. After being rectifier and filter the output is ready to be store in capacitor or used by low power appliances.

\section{RESEARCH METHOD}

In this study, lead zirconate titante (PZT) piezoelectric transducer has been used to harvest the kinetic energy from the footstep. The output voltage of this piezoelectric transducer is dependent to the structure of the ceramic and magnitude of strain and stress that applies on its structure. This transducer has diameter of $5 \mathrm{~cm}$ crystalline structure. The common output voltage is around 0-12 V. However at instant impact on this transducer, it can achieve until $30 \mathrm{~V}$ while the output current is about $5 \mathrm{~mA}$. There are two shape of PZT piezoelectric transducer that been considering in this study which are the circular shape and the square shape. The circular shape of piezoelectric transducer is more suitable to accept the stress or strain at 
the middle of the transducer meanwhile, the square shape of piezoelectric produce high output voltage when the strain or stress applied on the tip of the transducer.

This circular shape piezoelectric transducer has been choose because it is most suitable transducer for footstep rather than square piezoelectric transducer. The circular shape of piezoelectric give higher output voltage when testing on oscilloscope. This is due to the deflection on its structure when foot press is applied on it. The piezoelectric transducer is connected in series-parallel connection where the value of voltage as well as current output are both satisfactory. The output of the piezoelectric is in AC form. Before being stored in storage components such as battery or capacitor, it needs to be rectified into DC form then, supply it to the DC loads. In this study, the full wave bridge rectifier was used to rectify the output from the piezoelectric tile. The full wave bridge that is used in the study consist of four diodes and two capacitors as shown in Figure 1. One of the capacitors acts as smoothing capacitor to filter the output waveform and another one as a storage component to store the energy.

This full wave bridge rectifier operation is divided into two-cycle which are positive half-cycle and negative half-cycle. The four diodes labelled D1 to D4 are arranged in "series pairs" with only two diodes conducting current during each half cycle. During the positive half cycle of the supply, diodes D1 and D2 conduct in series while diodes D3 and D4 are in OFF condition as they are now in reserve biased and the current flows through the two capacitors. During the negative half cycle of the supply, diodes D3 and D4 conduct in series as they are in forward biased, but diodes D1 and D2 are in reverse biased. The current flowing through the capacitors is the same direction as before. One of the capacitor acts as smoothing filter and another one acts as storage element. Both of them are connected in parallel. The voltage in the AC form is being rectified in the DC form in full brigde rectifier circuit, then it goes to the smoothing capacitor to remove any ripple factor that still left in the DC voltage form after the rectifier process. Lastly, the output from the piezoelectric tile is stored in the storage capacitor and ready to be used by another low power devices. The experiment setup of the piezoelectric tile as shown in Figure 2.

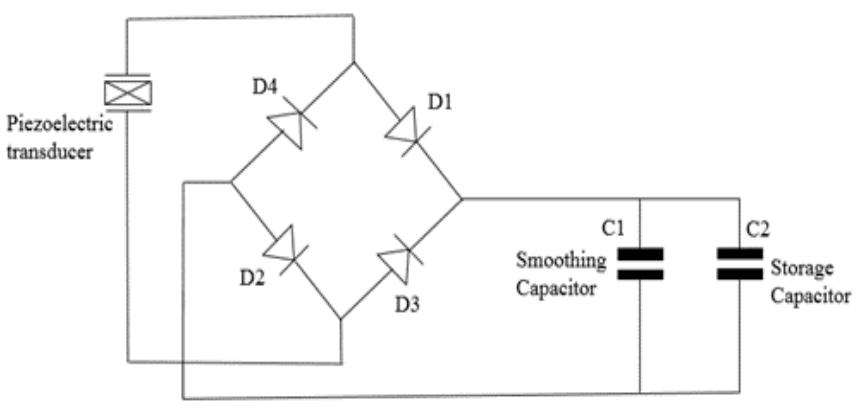

Figure 1. Diagram of the full-wave bridge rectifier with smoothing and storage capacitor

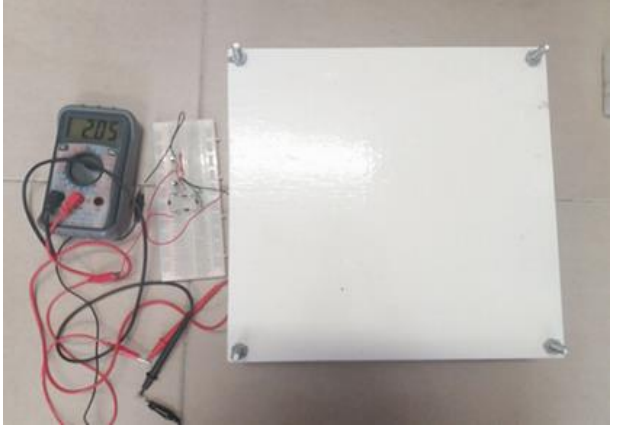

Figure 2. The experiment setup of the piezoelectric tile

\section{RESULTS AND ANALYSIS}

The piezoelectric transducer output is in $\mathrm{AC}$ waveform. The output of the transducer needs to be rectify and filtered before being used to the storage or to the DC loads. Figure 3 shows the output of the piezoelectric transducer before being inserted to the full bridge rectifier.

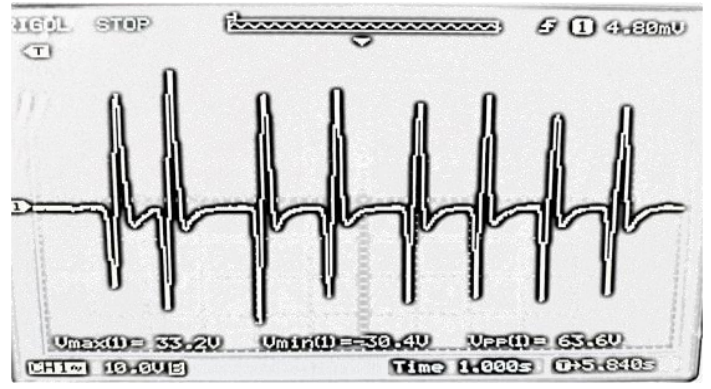

Figure 3. The output of the piezoelectric transducer before being rectifiy 


\subsection{Connection of Piezoelectric}

The piezoelectric transducer was connected in series and parallel connection. Before using the piezoelectric transducer to generate electric energy, the connection needs to be determined to choose the better output from the piezoelectric transducer. Figure 4 shows three piezoelectric transducers were connected in series. Figure 5 shows, three piezoelectric transducers are connected in parallel connection. Two sets of three piezoelectrics that connected in series were attached in parallel for series-parallel connection as shown in Figure 6. The multimeter was connected to the piezoelectric transducers to measure the voltage and current across the connection. A double-sided tape $3 \mathrm{~mm}$ is placed on the top and the bottom of the piezoelectric transducer to maximize the output of this transducer. Figure 7 and Figure 8 shows the output of the piezoelectric based on the connection that being done.

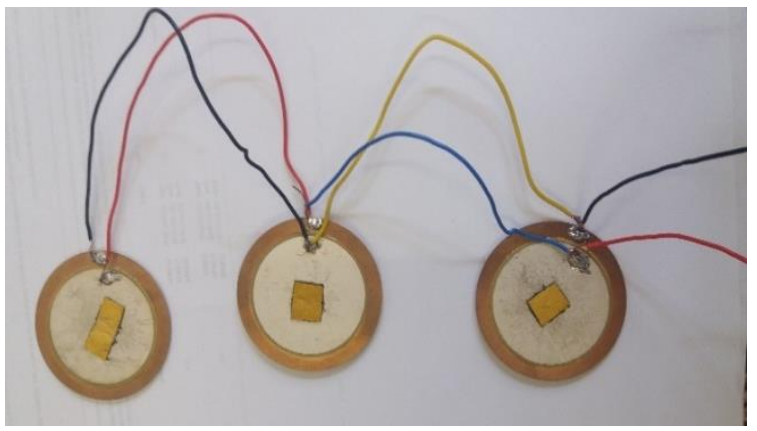

Figure 4. The series connection of piezoelectric transducer

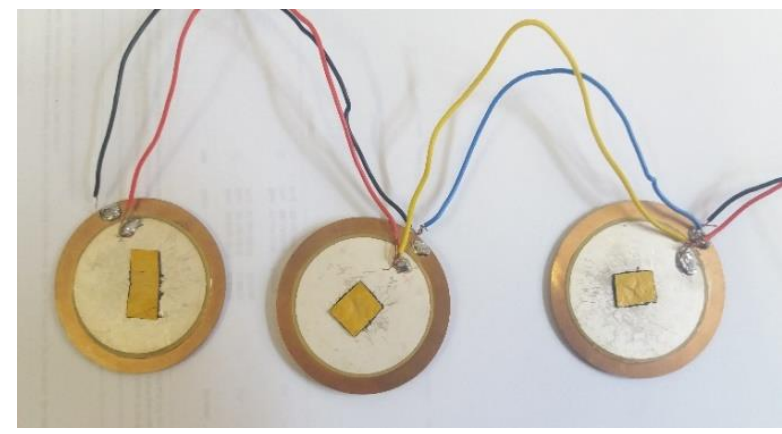

Figure 5. The parallel connection of piezoelectric transducer

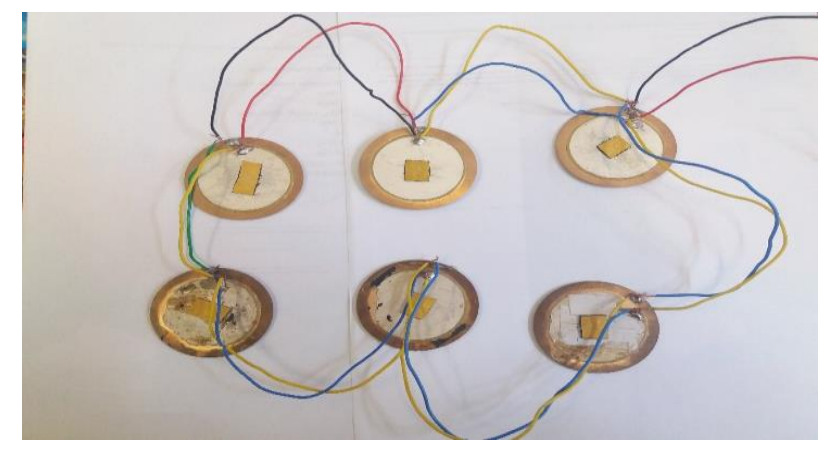

Figure 6. The series-parallel connection of piezoelectric transducer

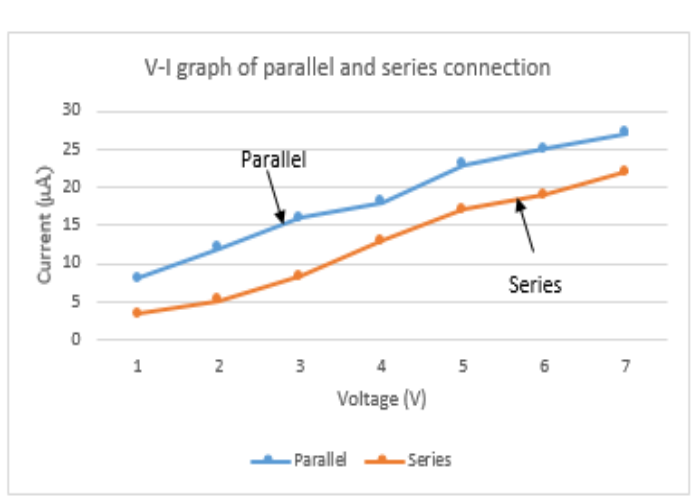

Figure 7. Voltage - Current graph of parallel and series connection of piezoelectric

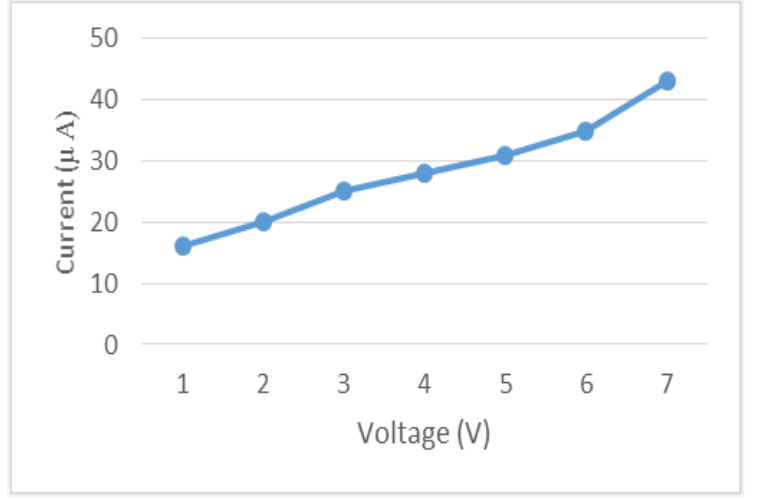

Figure 8. Voltage - Current graph of series-parallel connection of piezoelectric 
Figure 7 shows that when the piezoelectric are connected in series the output voltage is high but the output current is low. However, vice versa happened for the parallel connection of the piezoelectric transducer. It give high current but low output voltage. In order to solve this problem, the combination of this connection needs to carry out. Two set of three piezoelectric transducers that connected in series was attached together in parallel to form series-parallel connection. The value of voltage as well as current output are both satisfactory.

\subsection{Analysis on the Piezoelectric Tile}

The piezoelectric tile that show on the Figure 9 is used for foot press or pumping activites in order to collect the voltage. The 6 cell of piezoelectric transducers is placed between the upper and lower of this piezoelectric tile. This piezoelectric tile is design in a square shape with wood block. This tile are screw at its four edge and combine with the spring to make the upper tile bounce back after the person step on it. The piezoelectric transducer is placed between the gaps of the two tiles. The subjects are asked to do the foot press or pumping activities on this piezoelectric tile to collect the voltage produced by the 6 cell piezoelectric transducers during that activities. Figure 10 show the model of the piezoelectric tile from front, side and inside view.

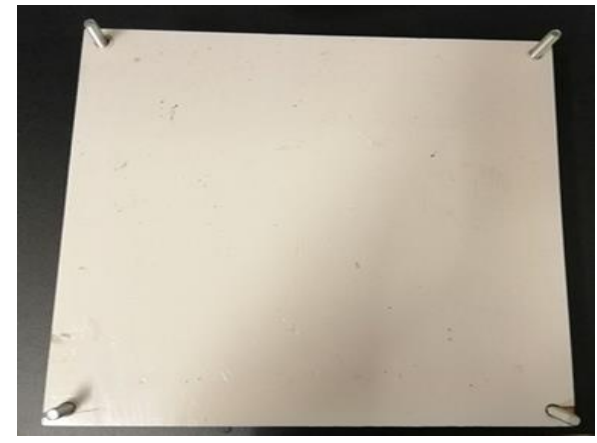

Figure 9. The piezoelectric tile that used for foot press activities

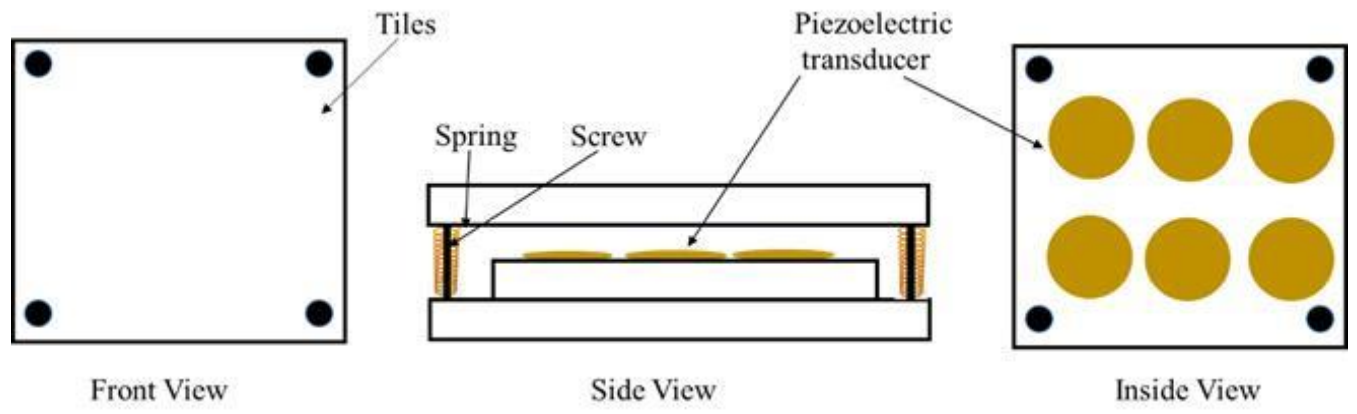

Figure 10. Model of piezoelectric tile with 6 cell of piezoelectric tile

Table 1. The Weight and the Voltage Taken based on the Jump on the Piezoelectric

\begin{tabular}{cccccc}
\hline Subject & Weight $(\mathrm{kg})$ & \multicolumn{4}{c}{ Time $(\mathrm{sec})$} \\
& & $5 \mathrm{sec}$ & $10 \mathrm{sec}$ & $15 \mathrm{sec}$ & $20 \mathrm{sec}$ \\
\hline Subject 1 & 45 & $1.98 \mathrm{~V}$ & $2.15 \mathrm{~V}$ & $2.80 \mathrm{~V}$ & $3.78 \mathrm{~V}$ \\
Subject 2 & 50 & $0.83 \mathrm{~V}$ & $1.23 \mathrm{~V}$ & $2.38 \mathrm{~V}$ & $3.12 \mathrm{~V}$ \\
Subject 3 & 55 & $1.76 \mathrm{~V}$ & $2.73 \mathrm{~V}$ & $4.66 \mathrm{~V}$ & $5.65 \mathrm{~V}$ \\
Subject 4 & 60 & $2.75 \mathrm{~V}$ & $4.59 \mathrm{~V}$ & $5.31 \mathrm{~V}$ & $6.06 \mathrm{~V}$ \\
\hline
\end{tabular}

Study using foot press or pumping is conducted to determine the voltage output of a 6 cell of the piezoelectric transducer that connected in series-parallel connection. Table 1 shows subject with $45 \mathrm{~kg}$, $50 \mathrm{~kg}, 55 \mathrm{~kg}$ and $60 \mathrm{~kg}$ body weight are used to test the piezoelectric tile. They are asked to step on the tiles to do the foot press or pumping activities to test the voltage generating capacity of the piezoelectric tile. 
The voltage generated is based on the time recorded which are $5 \mathrm{sec}, 10 \mathrm{sec}, 15 \mathrm{sec}$, and $20 \mathrm{sec}$. The relation between the time taken and the voltage being generated is plotted in the graph for each weight. From Figure 11, it can be seen that maximum voltage is generated when the person pumps about 20 seconds on the piezoelectric tile. It also can be concluded that the force that is applied by every subject are variant. The voltage generated depends on the force that being applied to the piezoelectric tile. In theory when a bigger person pump on this piezoelectric tile, the voltage that is generated is higher compared to the smaller person. There are a linear relation between the force and the voltage generated. Figure 11 shows that the theory is proved. The weight of subject 4 is bigger than other subjects so it the voltage that generates by this subject is the highest when the subject pump on the tile.

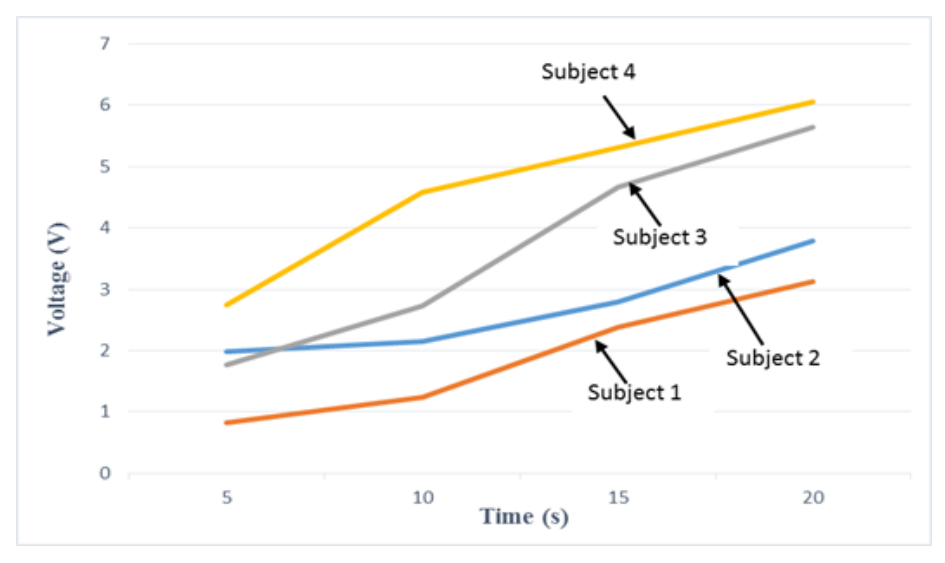

Figure 11. Voltage against time measured during subject press on the piezo tile

\section{CONCLUSION}

A piezoelectric tile is capable of generating more voltage when longer the time taken. The longer the time taken means more footstep/force are applied on the tile. The linear relation is found between the voltage generated and the time taken. This piezoelectric are specifically suitable for the implementation in the crowded area such as pavement street, train ticket counter, stairs and dance floor. The piezoelectric tile is also suited for the exercise tile such as for skipping or on the treadmill. The power that is generated from this piezoelectric tile can be used to power up the light street, light along the stairs and also low power appliances.

\section{ACKNOWLEDGEMENTS}

The authors gratefully acknowledge the supports of the Malaysian Ministry of Higher Education (MOHE) through FRGS Research Grant No. 1615 and the Universiti Tun Hussein Onn Malaysia through Short Term Grant No. U541.

\section{REFERENCES}

[1] M. Nitashree, et.al., "Foot Step Power Generation Using Piezoelectric Material," International Journal of Advanced Research in Electronics and Communication Engineering, vol. 4, pp. 2503-2506, Oct 2015.

[2] D. Marshiana, et al., "Footstep Power production using Piezoelectric Sensors," Research Journal of Pharmacy and Technology, vol 9, pp. 831-834, Jul 2016.

[3] V. Panneerselvam, et al., "Portable DC Regulated Power Supply from Footsteps," International Journal for Scientific Research \& Development, vol 5, pp. 916-918, April 2017.

[4] R. Prabaharan, et.al., "Power Harvesting By Using Human Foot Step," International Journal of Innovative Research in Science, Engineering and Technology, vol 2, pp 3001-3009, Jul 2013.

[5] P. Madhu, et al., "Electrical Power Generation by Foot-steps using Piezo-electric Transducers," International Journal of Recent Trends in Engineering \& Research (IJRTER) vol. 2 pp 108 - 115, June 2016.

[6] C. Gautam, et.al., "Power Harvesting Through Human Locomotion," International Journal of Advanced Research in Electrical, Electronics and Instrumentation Engineering, vol 6, pp. 2277-2282, April 2017.

[7] R. M. Mahidur and R. Sarker, "Vibration Based Piezoelectric Energy Harvesting Utilizing Bridgeless Recitifier Circuit," Jurnal Kejuruteraan, pp. 87-94, 2016. 
[8] E. Bischur, and N. Schwesinger, "Energy harvestingfrom floor using organic piezoelectric modules," 2012 Power Engineering and Automation Conference, 2012, pp 978-981.

[9] E. Maghsoudi, et al., "A review of walking energy harvesting using piezoelectric materials," IOP Conference Series: Materials Science and Engineering, 2017, pp 1-8.

[10] M.N.Gupta, et al., "Electricity Generation Due to Vibration of Moving Vehicles Using Piezoelectric Effect," Electricity Generation Due to Vibration of Moving Vehicles Using Piezoelectric Effect, vol. 4 pp. 313-318. 2014.

[11] Y. Tsujiura, et al., "Comparison of effective transverse piezoelectric coefficients e31, f of $\mathrm{Pb}(\mathrm{Zr}, \mathrm{Ti}) \mathrm{O}$ thin films between direct and converse piezoelectric effects," Japanese Journal of Applied Physics, vol 54 pp 1-8. 2016.

[12] A. Majeed, "Piezoelectric Energy Harvesting for Powering Micro Electromechanical Systems (MEMS)," Journal of Undergraduate Research, vol 5, pp 1-5.

[13] D. Vatansever, et al., "Alternative Resources for Renewable Energy: Piezoelectric and Photovoltaic Smart Structures, Global Warming," - Impacts and Future Perspectives, 2012, pp. 264-268.

[14] P. Arora, et al., "Piezoelectrics - A Potential Electric Source for Aircrafts," Proceedings of the World Congress on Engineering, 2013, pp. 978-980.

[15] V. Rathod, et al., "Power Generation Using Piezoelectric Material," International Research Journal of Engineering and Technology, vol. 5, pp 87-90, 2018.

[16] V. Prasannabalaji, et al, "Staircase Power Generation Using Piezo-Electric Transducers," Advance in Electronic and Electric Engineering, vol. 3, pp. 747-754, 2013.

[17] A. Kokkinopoulos, et.al., "Energy harvesting implementing embedded piezoelectric generators - The potential for the Attiki Odos traffic grid," TerraGreen 13 International Conference 2013 - Advancements in Renewable Energy and Clean Environment, 2013, pp. 1-17

[18] K. Boby, et al., "Footstep Power Genration Using Piezo Electric Transducers". International Journal of Engineering and Innovative Technology, vol 3, pp. 264-267, April 2014.

[19] Y. Motey, et.al., "Footstep Power Genration System," International Journal of Innovations in Engineering and Science, vol. 2, pp. 177-180, 2017.

[20] J. Varghese and P. Karikottil, "Footstep Power Generation using Piezoelectric Sensors," International Journal of Recent Innovation in Engineering and Research, vol. 2, pp 11-16, 2017.

[21] A. Arvind, et al., "Power Generation through Human Locomotion," Journal of Electronics and Communication Systems, vol. 1, pp 1-9, 2016.

[22] J. Ghosh, et al., "Electrical Power Generation Using Foot Step for Urban Area Energy Applications," 2013 International Conference on Advances in Computing, Communications and Informatics (ICACCI), 2013, pp 1367-1369.

[23] R. Meier, et.al., "A Piezoelectric Energy-Harvesting Shoe System for Podiatric Sensing," Proceedings of IEEE 36th Annual International Conference of Engineering in Medicine and Biology Society (EMBC 2014), 2014, pp $622-625$

[24] A. Kamboj, et al., "Design of footstep power generator using piezoelectric sensors," 2017 International Conference on Innovations in information Embedded and Communication Systems (ICIIECS), 2017, pp 978-980.

[25] HR Nayan, "Power Generation Using Piezoelectric Material," Journal of Material Sciences \& Engineering Journal of Material Sciences \& Engineering, vol 4, pp 1-4, 2015. 